\title{
Sustainable Cryptography
}

\author{
Johannes Buchmann
}

\begin{abstract}
Cryptography is a fundamental tool for cybersecurity and privacy which must be protected for long periods of time. However, the security of most cryptographic algorithms relies on complexity assumptions that may become invalid over time. In this talk I discuss how sustainable cybersecurity and privacy can be achieved in this situation.
\end{abstract}

Open Access This chapter is licensed under the terms of the Creative Commons Attribution 4.0 International License (http://creativecommons.org/licenses/by/4.0/), which permits use, sharing, adaptation, distribution and reproduction in any medium or format, as long as you give appropriate credit to the original author(s) and the source, provide a link to the Creative Commons license and indicate if changes were made.

The images or other third party material in this chapter are included in the chapter's Creative Commons license, unless indicated otherwise in a credit line to the material. If material is not included in the chapter's Creative Commons license and your intended use is not permitted by statutory regulation or exceeds the permitted use, you will need to obtain permission directly from the copyright holder.

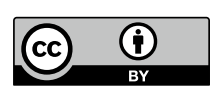

J. Buchmann ( $)$

Technical University of Darmstadt, Hochschulstr. 10, 64289 Darmstadt, Germany

e-mail: johannes.buchmann@tu-darmstadt.de

T. Takagi et al. (eds.), International Symposium on Mathematics,

Quantum Theory, and Cryptography, Mathematics for Industry 33,

https://doi.org/10.1007/978-981-15-5191-8_1 